\title{
An Omphalocele, Epispedias, Cleft Palate, Cranial deformity and Facial Dysmorphism: A Case with Midline and Laterality Defects
}

\author{
L. B. L. Prabodha1 ${ }^{1}$ T. S. D. Amarasena' ${ }^{2}$ I. Ilayperuma ${ }^{1}$ B. G. Nanayakkara ${ }^{1}$
}

\begin{abstract}
A 7 year old male child with cleft soft palate, omphalocele, epispedias, posterior prominence of the skull, prominent forehead with high anterior hair line, dextraposition of the heart, right sided inguinal hernia, mental retardation, generalized hypotonia and flexion deformity of both toes and fingers presented to the paediatric clinic, Teaching Hospital Karapitiya, for the follow up management. Furthermore, the child had subtle dysmorphic features including, broad nasal bridge, hypertelorism and low set ears. He was the second child of the family and there were no other family history of congenital anomalies. The karyotype was 46XY. Mutations in chromosome bands 3p12-21, ZIC3 gene in human X chromosome and WolfHirschhorn syndrome involving heterozygous deletion of $4 \mathrm{p} 16.3$ region ( $4 \mathrm{p}$ syndrome) can be presented with above clinical features and it is necessary to investigate the patient further for the genetic involvement.
\end{abstract}

Key words: omphalocele, epispedias, cleft palate, cranial deformity, facial dysmorphism, ZIC3 gene, $4 p$ syndrome

\section{INTRODUCTION}

Disturbances of the normal asymmetric position of organs or situs inversus, have been described as laterality defects. Congenital anomalies of midline structures such as, esophageal defects, anal defects, neural tube defects, cleft lip and palate are considered as midline defects. Animal model studies and human birth defect registries suggest that the midline and laterality defects are etiologically related (1).

All vertebrates have a body configuration with a midline and left and right halves that are symmetric for most external features. Many internal organs have asymmetric placement in the body with respect to the midline. The heart is positioned in the left side of the thorax with its apex pointed towards the left. The spleen and stomach are placed on the left side, liver in the right side of the abdomen. Alterations of the left/right (LR) asymmetry may cause alteration of the position of organs (heterotaxia or situs ambiguous) or they may produce reversal of LR organ position (situs inversus). Disturbances of LR asymmetry may also be limited to a single asymmetric organ such as the heart in individuals with isolated dextrocardia or dextropositon of the heart. Collectively, any abnormalities of LR asymmetry are referred to as a laterality defect (1). It has been recognized that there is a genetic basis for some disturbances of LR asymmetry in humans. Although most cases are considered sporadic, families with laterality defects have been shown to have an autosomal dominant, autosomal recessive and $\mathrm{X}$ linked recessive inheritance patterns. Thus,

${ }^{1}$ Molecular Genetics Laboratory, Department of Anatomy, University of Ruhuna.

${ }^{2}$ Department of Paediatrics, University of Ruhuna. 
PRAbOdHA, L. B. L., AMARASENA, T. S. D., ILAYPERUMA, I., NANAYAKKARA, B. G., An omphalocele, epispedias, cleft palate, cranial deformity and facial dysmorphism: A Case with Midline and Laterality Defects. Sri Lanka Anatomy Journal (SLAJ), 1(2): 5860, 2017.

multiple genes exist that are responsible for human laterality defects, although mutations of single genes may cause laterality defects that can be seen as Mendelian patterns (2,3). Genes corresponding to the chromosome bands 3 p12-3p21 has been described in the literature causing midline and laterality defects. Furthermore, mutations in ZIC3 gene in human $\mathrm{X}$ chromosome have been identified in causing midline and laterality defects (4).

There is clear evidence that model animals with disturbances of LR asymmetry to have midline defects more commonly than expected by chance. Some of these defects include neural tube defects, oral clefts, omphalocele, esophageal atresia /tracheoesophageal fistula, imperforate anus, epispedias conotruncal heart defects, diaphragmatic hernia (5).

Four families with a distinctive malformation syndrome which includes diaphragmatic defects, limb deficiencies and ossification defects of the Skull were also reported (6).

Wolf-Hirschhorn syndrome (WHS) is characterized by typical craniofacial features in infancy consisting of wide bridge of the nose continuing to the forehead, microcephaly, high anterior hairline with prominent glabella, widely spaced eyes, epicanthic folds, high arched eyebrows, short philtrum, downturned corners of the mouth, micrognathia, and poorly formed ears with pits and tags. The diagnosis of Wolf-Hirschhorn syndrome is established by detection of a heterozygous deletion of the Wolf-Hirschhorn syndrome critical region (WHSCR) within 4 p16.3 at 1.4-1.9 $\mathrm{Mb}$ from the terminus (7).

\section{CASE REPORT}

Index case was a 7 year old male child with cleft soft palate, Omphalocele, epispedias, right sided inguinal hernia, posterior prominence of the skull, prominent forehead with high anterior hair line, mental retardation, hypotonia, dextraposition of the heart, flexion deformity of both toes and fingers. Furthermore, he has having subtle dysmorphic features such as, broad nasal bridge, hypertelorism and low set ears. He was born at term with a birth weight of $2.4 \mathrm{~kg}$. He was presented with global developmental delay. No other respiratory or gastro intestinal defects. He was the second child of the family with no other family history of congenital anomalies. His elder brother was apparently normal. Echo cardiogram of the child reveled dextraposition of the heart and no other congenital cardiac anomalies were present. Ultra sound scan of the abdomen revealed normal. His karyotype was 46XY.

The following differential diagnoses were made:

1) Mutations in chromosome bands $3 \mathrm{p} 12$ 21 causing midline and laterality defects.

2) Mutations in ZIC3 gene in human $X$ chromosome causing midline and laterality defects.

3) Wolf-Hirschhorn syndrome involving heterozygous deletion of $4 \mathrm{p} 16.3$ region (4p syndrome).

The omphalocele, cleft palate and epispediasis were treated by the Pediatric and the Maxio-Facial surgeons at the Teaching Hospital Karapitiya. The child was followed up in the Rheumatology clinic and the Physiotherapy department for his rehabilitation. 
PRABODHA, L. B. L., AMARASENA, T. S. D., ILAYPERUMA, I., NANAYAKKARA, B. G., An omphalocele, epispedias, cleft palate, cranial deformity and facial dysmorphism: A Case with Midline and Laterality Defects. Sri Lanka Anatomy Journal (SLAJ), 1(2): 58$60,2017$.

\section{DISCUSSION AND CONCLUSION}

According to the reported literature there is clear evidence that midline and laterality defects occur together more commonly than expected by chance (5). The midline defects include neural tube defects, oral clefts, omphalocele, esophageal atresia/ tracheoesophageal fistula, imperforate anus, epispedias, conotruncal heart defects, diaphragmatic hernia whereas the laterality defects include dextraposition of heart, malrotation of gut and other dextraposition of viscera such as right sided spleen (5). It was stated that the mutations in chromosome bands 3p12-21 causing midline and laterality defects associate together more frequently. Furthermore, it was reported that mutations in ZIC3 gene in human $\mathrm{X}$ chromosome causing midline and laterality defects in some families (1).

The $4 p$ syndrome or Wolf-Hirschhorn syndrome is characterized by typical craniofacial features and other abnormalities in infancy (7).

The index case also has shown some clinical features such as, dextraposition of the heart, omphalocele, epispedias, congenital inguinal hernia, cleft palate, facial dysmorphism and cranial anomalies, in favor of the above mentioned differential diagnosis. Furthermore, his karyotyping was $46 \mathrm{XY}$.

Molecular genetics investigations are important in this case for diagnosing the condition and to identify the etiology of the anomalies.

\section{REFERENCES}

1. Morelli SH, Young L, Reid B, Ruttenberg $\mathrm{H}$, Bamshad MJ. American clinical analysis of families with heart, midline and laterality defects. Journal of Medical Genetics 2001; 101: 388-392.
2. Casey B, Cuneo BF, Vitali C, van Hecke H, Barrish J, Hicks J, Ballabio A, Hoo JJ. Autosomal dominant transmission of familial laterality defects. Am J Med Genet 1996; 61: 325-328.

3. Debrus S, Sauer U, Gilgenkrantz S, Jost $\mathrm{W}$, Jesberger HJ, Bouvagnet P.. Autosomal recessive lateralization and midline defects: blastogenesis recessive 1 . Am J Med Genet 1997; 68: 401-404.

4. Gebbia M, Ferrero GB, Pilia G, Bassi MT, Aylsworth A, Penman-Splitt M, Bird LM, Bamforth JS, Burn J, Schlessinger D, Nelson DL, Casey B. X-linked situs abnormalities result from mutations in ZIC3. Nat Genetics 1997; 17: 305-308.

5. Khoury MJ, Cordero JF, Mulinare J, Opitz JM. Selected midline defect associations: a population study. Pediatrics 1989; 84: 266-72.

6. Froster U. G, Kolditz P, Wisser J, Robbiani M. B, Stallmach T, Hebisch G, Huch R, Huch A. Diaphragmatic Defects, Limb Deficiencies, and Ossification Defects of the Skull: A Distinctive Malformation Syndrome. American Journal of Medical Genetics. 1996; 62: 4853.

7. Battaglia A, Carey J. C, South S. T. WolfHirschhorn Syndrome. GeneReviews. http://www.ncbi.nlm.nih.gov/books/NBK1 183/\#. Accessed on 01. 09. 2015.

\section{CORRESPONDENCE}

Dr. L. B. L. Prabodha

Molecular Genetics Laboratory,

Department of Anatomy,

University of Ruhuna, Sri Lanka.

E mail-1ahiruprabodha@gmail.com

Received: September 2017

Accepted: September 2017 